\title{
CONCEPÇÕES DOS FAMILIARES DE USUÁRIOS ACERCA DO CUIDADO OFERECIDO EM CENTRO DE ATENÇÃO PSICOSSOCIAL*
}

Johana Maria Oliveira de Andrade', Priscilla Maria de Castro Silva², Elisângela Braga de Azevedo ${ }^{3}$, Renata Cavalcanti Cordeiro $^{4}$, Raissa Barbosa de Andrade ${ }^{5}$, Maria de Oliveira Ferreira Filha ${ }^{6}$

RESUMO: Trata-se de um estudo de caso, exploratório, com abordagem qualitativa, desenvolvido em um Centro de Atenção Psicossocial da Região Nordeste brasileira com 20 familiares dos usuários. Objetivou-se analisar as concepções acerca do cuidado oferecido; identificar se os familiares percebem que os profissionais do Centro contribuem para a promoção da autonomia e inclusão social dos usuários; e averiguar em que medida o grupo de família tem sido uma estratégia eficaz para a promoção do cuidado aos usuários. O material empírico foi produzido por meio de entrevistas semiestruturadas, entre agosto e setembro de 2010, e submetido à análise de conteúdo. Os resultados demonstraram que a participação no grupo de família possibilitou que os familiares contribuíssem com o tratamento proposto, tornando-se corresponsáveis no processo de cuidado oferecido. Os familiares foram estimulados para a promoção da autonomia e inclusão do usuário na sociedade.

DESCRITORES: Serviços de saúde mental; Família; Grupos de autoajuda.

\section{SERVICE USERS' FAMILIES' CONCEPTIONS OF THE CARE OFFERED IN A PSYCHO- SOCIAL CARE CENTER}

ABSTRACT: This is an exploratory case study with a qualitative approach, undertaken in a psycho-social care center in the North-Eastern region of Brazil, with 20 family members of service users. The objective was to analyze their conceptions regarding the care offered; to identify whether the family members perceived that the professionals at the Centercontribute to the promotion of the service users' autonomy and social inclusion; and to check to what extent the family group has been an efficient strategy for promoting the care for the service users. The empirical material was produced through semi-structured interviews held between August and September 2010, and submitted to content analysis. The results show that the participation in the family group made it possible for families to contribute to the treatment proposed, becoming coresponsible in the care process offered. The family members were encouraged to promote the service user's autonomy and inclusion in society. DESCRIPTORS: Mental health services; Family; Support groups.

\section{CONCEPCIONES DE LOS FAMILIARES DE USUARIOS ACERCA DEL CUIDADO OFRECIDO EN CENTRO DE ATENCIÓN PSICOSOCIAL}

RESUMEN: Este es un estudio de caso, exploratorio, con abordaje cualitativo, desarrollado en un Centro de Atención Psicosocial de la Región Nordeste brasileña con 20 familiares de los usuarios. La finalidad fue analizar las concepciones acerca del cuidado ofrecido; identificar si los familiares perciben que los profesionales del Centro contribuyen para la promoción de la autonomía e inclusión social de los usuarios; y averiguar en qué medida el grupo de familia es una estrategia eficaz para la promoción del cuidado a los usuarios. El material empírico fue producido por medio de entrevistas semiestructuradas, entre agosto y septiembre de 2010, y sometido al análisis de contenido. Los resultados muestran que la participación en el grupo de familia ha posibilitado que los familiares contribuyeran con el tratamiento propuesto, volviéndose corresponsables en el proceso de cuidado ofrecido. Los familiares fueron estimulados para la promoción de la autonomía e inclusión del usuario en la sociedad. DESCRIPTORES: Servicios de salud mental; Familia; Grupos de apoyo.

*Este artigo é um recorte do trabalho de conclusão de curso do Departamento de Enfermagem da Faculdade de Ciências Médicas de Campina Grande - PB intitulado 'Análise das concepções dos familiares dos usuários acerca do tratamento realizado no CAPS'.

\footnotetext{
${ }^{1}$ Enfermeira.

${ }^{2}$ Enfermeira. Mestranda pelo Programa de Pós-Graduação em Enfermagem da Universidade Federal da Paraíba - UFPB. Professora da Universidade Federal de Campina Grande - UFCG. Membro do Grupo de Estudos e Pesquisas em Saúde Mental Comunitária da UFPB. ${ }^{3}$ Enfermeira. Doutoranda pelo Programa de Pós-Graduação em Enfermagem da UFPB. Professora do Departamento de Enfermagem da Universidade Estadual da Paraíba - UEPB. Membro do Grupo Estudos e Pesquisas em Saúde Mental Comunitária da UFPB.

${ }^{4}$ Enfermeira. Mestranda pelo Programa de Pós-Graduação em Enfermagem da UFPB. Membro do Grupo de Estudos e Pesquisas em Saúde Mental Comunitária da UFPB.

${ }^{5}$ Acadêmica em Enfermagem da UEPB.

${ }^{6}$ Enfermeira. Doutora em Enfermagem. Professora do Departamento e do Programa de Pós-Graduação em Enfermagem da UFPB. Líder do Grupo de Estudos e Pesquisa em Saúde Mental Comunitária.
} 


\section{INTRODUÇÃO}

A Psiquiatria clássica considerava a 'loucura' como doença, erro absoluto, distúrbio da razão, perda do juízo, incapacidade civil, irresponsabilidade social e jurídica. Com essas percepções, criou-se, para a pessoa que possui algum transtorno mental, um lugar de exclusão, isento de trocas sociais, designado como o hospital psiquiátrico, conhecido, também, como manicômio ${ }^{(1)}$. Nestes, os indivíduos eram excluídos do meio social, sendo a família, colocada num papel passivo de espera dos resultados apontados pelo saber psiquiátrico ${ }^{(2)}$.

A Reforma Psiquiátrica emergiu, portanto, como transformador de paradigmas na saúde mental, por ter como foco principal o cuidado integral e a reinserção psicossocial, transferindo o tratamento hospitalocêntrico para o meio comunitário ${ }^{(3)}$.

Assim, o Movimento da Reforma Psiquiátrica trouxe consigo a revalorização da família como apoiadora fundamental no cuidado da pessoa com algum transtorno mental e a própria ressignificação do ato cuidador, buscando, assim, enfrentar a cultura manicomial. Tal enfrentamento se dá por meio de uma rede de serviços que substituem as internações, realizando o cuidado no interior da família e no território, a partir da utilização de recursos da própria comunitária e das redes sociais.

Nessa nova perspectiva, os serviços substitutivos ao modelo psiquiátrico tradicional têm se expandido no Brasil, tendo como seu maior expoente os Centros de Atenção Psicossocial (CAPS), que variam de complexidade e especificidade, sendo generalista, específico para usuários de álcool e drogas, para crianças e adolescentes. Ainda, Hospitais-Dia, leitos psiquiátricos em Hospitais Gerais, Emergências Psiquiátricas, as Residências Terapêuticas e os Centros de Convivência. Tais serviços têm como características a utilização de um conjunto de tecnologias terapêuticas e práticas psicossociais destinadas a propiciar a participação da família de uma maneira mais efetiva e a manter o usuário dos serviços de saúde mental no seu território de origem ${ }^{(4)}$.

Nesse sentido, os serviços substitutivos de saúde mental buscam novas estratégias e iniciativas de ajuda e suporte mútuo para, dessa forma, desempenharem projetos de inclusão e reabilitação psicossocial, tentando trazer a família como parte indispensável para a efetividade do cuidado em saúde mental ${ }^{(5)}$.

A família, na contemporaneidade, é incentivada a assumir papel de copartícipe na reabilitação e inclusão social, pois o cuidado familiar preserva as condições de saúde dos usuários, bem como, facilita a reconstrução identitária marcada pelo processo de adoecimento. O cuidado, nessa perspectiva, configura-se como uma resposta que envolve a atenção à pessoa e não apenas à doença ${ }^{(6)}$

É importante a compreensão do território e da comunidade de origem, pois estes são ímpares no tratamento, pelo fato de entender-se que a família, quando cuida, não o faz sozinha. A família está amparada por uma rede de relações sociais espontâneas e mobilizadora de recursos que estão além das circunstâncias imediatas. A rede serve de apoio em momentos de necessidades e de crise. Assim, essa rede passa a ser considerada um valioso recurso e a principal fonte de ajuda em que se constitui o contexto social ${ }^{(6)}$.

No entanto, uma das preocupações dos profissionais tem sido a dificuldade de inserção do familiar nesse processo, tendo em vista fatores socioculturais e despreparo na prestação do cuidado, ficando, muitas vezes, sobrecarregado emocional e fisicamente ${ }^{(7)}$. Desse modo, o convívio dos outros parentes com a família geralmente é difícil, devido ao déficit de informação de como lidar com a diferença, sendo imprescindível vincular-se à equipe de saúde mental.

A intervenção junto aos familiares requer não apenas orientá-los como cuidadores, mas como pessoas que também precisam de atenção. Faz-se necessário acolher o sofrimento do cuidador e minimizar sua sobrecarga emocional, oferecendo espaços acolhedores e facilitadores de ações e de trocas de experiências entre a família, comunidade e equipe de saúde. Isso objetiva o compartilhar dúvidas, angústias em um movimento de proximidade com o tratamento e em direção à autonomia dos pacientes e a diminuição do sofrimento familiar.

Em torno dessa discussão, e no que diz respeito à Reforma Psiquiátrica e à desinstitucionalização do paciente em sofrimento mental, bem como à inserção da família nesse cuidado, emerge o interesse por essa problemática. Com isso, revela-se a importância desta investigação, tendo em vista a necessidade de uma abordagem em relação à saúde mental mais humanizada, menos hospitalocêntrica, que permita à família refletir sobre a sua relação com o portador de transtorno mental.

Assim, objetivou-se analisar as concepções de familiares dos usuários acerca do cuidado oferecido no CAPS; identificar se os familiares percebem que os profissionais do CAPS contribuem para a promoção da autonomia e inclusão social dos usuários; e averiguar em que medida em grupo de família tem sido uma estratégia eficaz para a promoção do cuidado aos usuários. 


\section{MÉTODO}

Trata-se de um estudo de caso, exploratório, com abordagem qualitativa, desenvolvido em um CAPS do Município de Campina Grande, Estado da Paraíba, Brasil. O serviço conta com uma equipe interdisciplinar que atua em diversas atividades, entre elas, a escuta e apoio a grupos de famílias.

Fizeram parte desta pesquisa a totalidade, ou seja, 20 familiares dos usuários cadastrados no CAPS, os quais participavam do Grupo de Família, que estava em andamento no local pesquisado às quintas-feiras, das $14 \mathrm{~h}$ às $15 \mathrm{~h} 30 \mathrm{~min}$.

Os critérios de inclusão foram: 1) idade igual ou superior a 18 anos,e 2) participação no grupo de apoio a familiares oferecido pelo CAPS, durante pelo menos um ano. Após a assinatura do Termo de Consentimento Livre e Esclarecido deu-se início a realização das entrevistas semiestruturadas de caráter individual, as quais foram gravadas e transcritas na íntegra, tendo ocorrido entre setembro e outubro de 2010.

O material empírico foi analisado através da análise de conteúdo do tipo categorial temático ${ }^{(8)}$, com isso, foi realizada a categorização das informações segundo: homogeneidade, exaustividade, exclusividade, objetividade e adequação ou pertinência. Enquanto que, para sua apresentação, utilizou-se a técnica da narrativa que possibilita a confrontação de significados com a literatura pertinente ao tema discutido.

O estudo foi desenvolvido de acordo com os aspectos éticos de pesquisa envolvendo seres humanos recomendados pela resolução 196/96 do Conselho Nacional de Saúde, tendo sua coleta sido realizada após a obtenção do parecer favorável, emitido pelo Comitê de Ética em Pesquisa com Seres Humanos do Centro de Ensino Superior e Desenvolvimento, sob o protocolo n. 4434.0.000.405-10.

\section{RESULTADOS}

A partir dos depoimentos dos entrevistados foi possível identificar as concepções dos familiares em relação ao cuidado oferecido aos seus parentes usuários do CAPS, por revelar a contribuição deste serviço para a inclusão social dos portadores de transtornos mentais a partir do enfoque prioritário de reinserção social. Com esse entendimento, emergiram as categorias descritas adiante:

\section{As concepções dos familiares acerca do CAPS como Promotor da Autonomia e InclusãoSocial dos Usuários}

Esse potencial do serviço pode ser observado nas falas a seguir:

Vi mudanças sim [...]. Ele hoje sai de casa, passeia, vai ao cinema, não tem mais crises, está tudo muito bom. (F-02)

Ele está bem melhor, porque aqui ele é respeitado, é visto como pessoa, e não como um louco. (F-04)

Sim, sem dúvida nenhuma, se eu conhecesse o CAPS antes minha irmã não teria ido para João Pessoa para aquele hospital de doido tomar choque. Para quê choque? Então aqui eles tratam ela com amor, cuidado, paciencia, e os medicamentos que eles dão não são agressivos. Por isso aqui ela tá bem melhor. (F-03)

A partir dos relatos acima, identifica-se que o CAPS tornou-se um serviço acolhedor, que favorece mudanças no comportamento do usuário em sociedade, melhorando a qualidade de vida destes indivíduos, por proporcionar um cuidado humanizado e que desenvolve a autonomia.

Identificou-se, também, que a experiência da família junto ao CAPS tem proporcionado mudanças no comportamento em relação à pessoa com transtorno mental. Sua inclusão no processo terapêutico possibilitou a formação de novos conceitos e diminuição do preconceito vivenciado no próprio ambiente doméstico, conforme evidenciado na fala seguinte:

Então, o CAPS me ensinou a trazer ela para o meio, eu isolava ela de mim, trancava num quarto, e a partir do momento que conheci o CAPS e trouxe ela pra cá, passei a entender a doença e aprender a ajudar minha irmã. A enfrentar as crises dela sem isolar mais ela. Hoje ela já não vive mais trancada. (F-03)

Constata-se, pelo relato acima, a dificuldade que a família apresenta em lidar com o usuário, caracterizada pela relação distante e prejudicada, gerada, talvez, pelo desconhecimento em relação aos fatores clínicos do sofrimento mental e dos preconceitos relacionados a esta patologia. Motivo pelo qual a família, por vezes, lida com o indivíduo como sendo este anormal que não se encaixa na conjuntura familiar. Por isso, evidencia-se a importância da equipe de profissionais 
do CAPS construir um projeto terapêutico individual que aborde as demandas de cada usuário, incluindo os familiares nesse processo, com intuito de promover a integralidade do cuidado.

Dessa maneira, ratifica-se que os familiares ainda não estão envolvidos no novo paradigma de cuidado às pessoas com sofrimento mental, caracterizado pela inserção social e busca da autonomia do usuário, pois estes relacionam a assistência efetiva à inércia e à exclusão social do portador de transtorno mental.

Sei que o tratamento é muito vagaroso, mas não vejo melhoras não, ela não está bem não, antigamente ela tomava o remédio e ficava boazinha, hoje em dia ela não está bem não sei por que, não sei se são os médicos que não tão cuidando como deve, não sei! (F-10)

Com esse entendimento, a fala acima, faz alusão que o familiar ainda entende que seu parente deveria ser sedado e, com isso, ele não incomodaria mais.

\section{Grupo de Família como estratégia eficaz do CAPS para} a inclusão da família no Projeto Terapêutico do Usuário

Nessa perspectiva, o grupo tem auxiliado o familiar a conviver melhor com seu parente, como evidenciado nas falas adiante:

Envolve sim a família. É muito interessante porque estamos ao lado de pessoas que passam por problemas parecidos com os nossos. Aqui conseguimos desabafar, as orientações também que eles dão, contribuem bastante para a convivência com ele em casa. (F-02)

[...] é como se fosse minha outra casa, toda semana tenho que vir [...] foi aqui que encontrei o apoio que eu e ele precisávamos. (F-10)

Percebe-se, portanto, que a participação no Grupo de Família no CAPS tem contribuído para a melhora do convívio familiar e, também, para a construção de laços afetivos, no qual o grupo se fortalece a partir da ajuda mútua, pois vivenciam os mesmos problemas e juntos constroem as suas estratégias de enfrentamento.

Alguns dos participantes mostraram-se satisfeitos, relatando sentimentos desencadeados pela evolução do tratamento, comparando o CAPS à sua própria casa, um lugar onde se sentem bem, confortados, compreendidos, como é evidenciado nas seguintes falas:
O grupo de família nos ajuda muito, nos escuta, nos dá atenção e isso é bom porque trocamos experiências uns com os outros. Cada um ajuda o outro. (F-04)

Sim, meu filho tem depressão e em casa enxergavam ele como preguiçoso. Eu mesma, como mãe, demorei muito pra entender e aceitar que ele estava doente. A reunião de família me ajuda muito porque vejo as outras mães, cada uma contando sua história com seu familiar e à medida que vão contando, começo a pensar que com meu filho acontece mais ou menos do mesmo jeito. E assim, vamos nos ajudando. (F-09)

O familiar F-09 traduz a dificuldade da família em aceitar a presença do transtorno mental em um parente, temendo enfrentar as dificuldades e desafios impostos pela doença. Outro fator que leva à reflexão seria o enfrentamento social da 'loucura' que, ao longo de sua história, vem carregada de estigma e preconceitos.

\section{DISCUSSÃO}

O CAPS, como dispositivo substitutivo do modelo manicomial, tem seu cuidado centrado no acolhimento e no vínculo, tendo em vista seu objetivo principal que é promover a inserção social do usuário a partir de projetos terapêuticos, baseados nos princípios de cidadania e no desenvolvimento das potencialidades do portador de transtorno mental, sendo importante, assim, incluir a família nesse projeto como copartícipe no processo de cuidar $^{(9)}$.

Desse modo, é necessário que os profissionais que atuam no CAPS desenvolvam ações que envolvam os familiares, para que estes passem a atuar de forma efetiva nas atividades desenvolvidas pelo serviço, contribuindo para a reabilitação da saúde do usuário, como preconiza o novo modelo de cuidado à saúde mental ${ }^{(9)}$. Tais serviços possibilitam a oferta de ações inclusivas que incitam parcerias intersetoriais entre instituições de ensino e outros serviços de saúde de base primária, secundária e terciária, contribuindo, desse modo para a integralidade do cuidado ${ }^{(10)}$.

Após a inserção da pessoa com transtorno mental no CAPS foi possível identificar mudanças significativas na relação familiar cotidiana, devido ao fortalecimento de vínculos nos relacionamentos interpessoais, na participação efetiva dos usuários nas atividades diárias e de sua inserção, cada vez mais frequente, em ambientes públicos. O cuidado oferecido por este serviço visa trazer o usuário de volta à sociedade, a partir 
da promoção da autonomia, ampliando a capacidade do indivíduo de conduzir a própria vida, minimizando, assim, o estigma relacionado à 'loucura'(11).

Esse serviço pode ser caracterizado como uma rede social ampla e resolutiva, que proporciona acolhimento, apoio e orientação por parte dos profissionais, o qual tem possibilitado grande contribuição, para que a família também assuma o papel de cuidadora e se torne capaz de auxiliar o profissional atuante no serviço, na resolução dos problemas do cotidiano ${ }^{(5)}$.

Alguns relatos mostram a dificuldade da família em lidar com as diferenças dos indivíduos portadores de transtorno mental, a qual é permeada pelo descompasso temporal (paciente-família-sociedade), associado a sentimentos de culpa, de perda, pela dificuldade de comunicação e interação e pelos conflitos familiares. A não remissão dos sintomas, os fracassos sociais e o comportamento anormal do usuário contribuem para o surgimento de tensões no núcleo familiar, alterando, assim, a rotina cotidiana ${ }^{(5)}$.

Os profissionais do CAPS têm um papel terapêutico significativo na vida dos seus usuários e familiares, por serem responsáveis pelo acolhimento e atenção a essas pessoas, devido a seu compromisso em fortalecer e proteger os laços sociais do usuário com a sua família e comunidade, com a finalidade de produzir autonomia e lançar a proposta do indivíduo como protagonista do seu tratamento ${ }^{(12)}$. Assim, é indispensável por parte da equipe do CAPS identificar a compreensão que a família tem a respeito do transtorno mental e as possíveis formas do cuidado em saúde, conhecer os significados e experiências destas, e oferecer estratégias para lidar com o usuário, tendo em vista dificuldades na aceitação e enfrentamento ${ }^{(13)}$.

Os grupos terapêuticos caracterizam-se como estratégia eficaz para a promoção da saúde dos familiares das pessoas portadoras de transtorno mental, os quais por vezes, são acometidos pela sobrecarga ocasionada pelo manejo com o usuário, devido ao despreparo, diminuindo, assim, a qualidade de vida destes cuidadores e consequentemente influenciado negativamente no quadro psicossocial do usuário ${ }^{(14)}$.

Dessa forma, percebe-se que estes grupos atuam diminuindo a sobrecarga e aumentando a capacidade resiliente dos cuidadores, à medida que oferecem a oportunidade do conhecimento sobre a saúde mental e proporciona a construção de vínculos afetivos com a comunidade, facilitando o enfrentamento das dificuldades ao encontrar apoio nas redes sociais ${ }^{(15)}$.
Portanto, o estabelecimento de parcerias entre profissionais de saúde e familiares é importante por proporcionar ajuda, orientação quanto à doença e fortalecimento de vínculos, para que os cuidadores tomem atitudes eficazes no momento de crise, contribuindo com o processo de reabilitação do usuário ${ }^{(15)}$.

É válido destacar que essa forma de cuidado representa uma prática comprometida com o processo de transformação pessoal e coletivo, visando à autonomia e empoderamento das pessoas em busca da mudança da realidade local. Esta nova perspectiva de cuidado implica na desconstrução do modelo tradicional de atenção em saúde mental, por atuar de maneira menos excludente e no reconhecimento biopsicossocial e cultural dos usuários ${ }^{(16)}$.

Nesse sentido, identifica-se a necessidade de atenção especial da equipe de profissionais às famílias, visando fortalecer a rede de apoio, incluindo-as, assim, nos grupos e oficinas, cujo objetivo é auxiliar no processo de inclusão social do usuário, esclarecendo dúvidas acerca do comportamento, sintomas apresentados, uso de psicofármacos e os efeitos colaterais dos mesmos, como também, contribuindo para o melhor convívio da família com usuário por meio de visitas domiciliares para conhecer melhor a realidade da família ${ }^{(17)}$.

Frente aos relatos obtidos, é notável o respeito dos entrevistados em relação ao cuidado prestado aos usuários no CAPS. $O$ vínculo construído entre a instituição e a família possibilita ao serviço investir na atenção à família, diminuindo sua sobrecarga e potencializando, ainda mais, o cuidado aos indivíduos portadores de transtorno mental.

\section{CONSIDERAÇÕES FINAIS}

Analisando os achados deste estudo percebeu-se a satisfação dos familiares em relação ao cuidado oferecido pelos profissionais que atuam no CAPS, revelando, nas suas falas, evolução positiva do usuário após sua inserção no serviço. Com isso, o profissional deste serviço cumpre seu papel no cuidado em saúde mental, por desempenhar ações preconizadas pela Reforma Psiquiátrica, que tem como estratégia a articulação da família, dos profissionais e dos usuários, em busca da reabilitação e reinserção social.

Ao investigar como se apresenta a relação da família com o portador de transtorno mental no domicilio, após seu tratamento no CAPS, pode-se perceber que ocorreram mudanças na questão da diminuição da discriminação, em sua relação com o usuário e na 
maneira como esse é percebido no âmbito familiar. Tendo em vista seu poder na promoção da autonomia e da inclusão do usuário na sociedade, bem como, da família no tratamento do seu parente, tornando o Grupo de Família o fator responsável por esses avanços.

Identificou-se que o CAPS interage com a dinâmica familiar no processo de reabilitação das pessoas com transtorno mental, proporcionando cuidado integral. Nesta perspectiva, os entrevistados revelaram que o Grupo de Família tem sido efetivo como possibilitador de escuta, orientação, partilha de experiências, o que contribuiu e favoreceu mudanças no seu comportamento dos familiares para com usuários do CAPS.

Sugere-se que os profissionais que atuam no CAPS adotem medidas que incentivem uma maior adesão dos familiares no tratamento e no cuidado prestado aos portadores de transtornos psíquicos, pois tal intervenção visa não apenas a instrumentalizá-los como cuidadores, mas como pessoas que também precisam de cuidados e apoio para auxiliar no processo de reabilitação e inclusão social dos usuários.

\section{REFERÊNCIAS}

1. Amarante P. Reforma psiquiátrica e epistemologia. Cad. Bras. Saúde Mental. [Internet] 2009;1(1) [acesso em 26 abr 2012]. Disponível: http://portal.incubadora.ufsc.br/ index.php/cbsm/article/view/998/1107

2. Pegoraro RF. Papéis atribuídos à família na produção da loucura: algumas reflexões. Acad. Paul. Psicol. [Internet] 2009;29(2) [acesso em 26 abr 2012]. Disponível: http://pepsic.bvsalud.org/scielo.php?pid=S1415711X2009000200004\&script=sci_arttext

3. Moura SG, Ferreira Filha MO, Carvalho MAP. Evolução histórica da abordagem em saúde mental no Brasil: da reforma psiquiátrica aos dias atuais. Rev enferm UFPE online. [Internet] 2012;6(3) [acesso em 04 fev 2013]. Disponível: http://www.revista.ufpe.br/ revistaenfermagem/index.php/revista/article/view/2172

4. Ministério da Saúde (BR). Secretaria de Atenção à Saúde. DAPE. Saúde Mental no SUS: Os Centros de Atenção Psicossocial. Brasília (DF):Ministério da Saúde; 2004.

5. Borba LO, Paes MR, Guimarães AN, Labronici LM, Maftum MA. A família e o portador de transtorno mental: dinâmica e sua relação familiar. Rev Esc Enferm USP. [Internet] 2011;45(2) [acesso em $04 \mathrm{fev}$ 2013]. Disponível: http://www.scielo.br/pdf/reeusp/ v45n2/v45n2a19.pdf
6. Gutierrez DMD; Minayo MCS. Produção de conhecimento sobre cuidados da saúde no âmbito da família. Ciênc. saúde colet. [Internet] 2010;15(1) [acesso em 04 fev 2013]. Disponível: http://www.scielo.br/scielo. php?pid $=$ S1413-81232010000700062\&script $=$ sci_ arttext

7. Amendola F, Oliveira MAC, Alvarenga MRM. Influência do apoio social na qualidade de vida do cuidador familiar de pessoas com dependência. Rev Esc Enferm USP. [Internet] 2011;45(4) [acesso em 04 fev 2013]. Disponível: http://www.scielo.br/pdf/reeusp/ v45n4/v45n4a13.pdf

8. Bardin L. Análise de conteúdo. 70ª ed. Lisboa; 2009.

9. Bielemann VLM, Kantorski LP, Borges LR, Chiavagatti FG, Willrich JQ, Souza AS, et al. A inserção da família nos Centros de Atenção Psicossocial sob a ótica de seus atores sociais. Texto Contexto-Enferm. [Internet] 2009;18(1) [acesso em 04 fev 2013]. Disponível: http:// www.scielo.br/pdf/tce/v18n1/v18n1a16.pdf

10. Duarte MLC, Pinho LB, Miasso AI. Estágio do curso de especialização em saúde mental: relato de experiência em um CAPS. Cogitare enferm. [Internet] 2011;16(4) [acesso em 04 fev 2013]. Disponível:http://ojs.c3sl.ufpr. br/ojs2/index.php/cogitare/article/viewFile/25447/17072

11. Camatta MW, Schneider JF. O trabalho da equipe de um Centro de Atenção Psicossocial na perspectiva da família. Rev Esc Enferm USP. [Internet] 2009;43(2) [acesso em 04 fev 2013]. Disponível: http://www.scielo. br/pdf/reeusp/v43n2/a19v43n2.pdf

12. Mello MF, Mello AAF, Kohn R. Epidemiologia da saude mental no Brasil. Porto Alegre: Artmed; 2007.

13. Sant'Ana MM, Pereira VP, Borenstein MS, Silva AL. O significado de ser familiar cuidador do portador de transtorno mental. Texto Contexto-Enferm. [Internet] 2011; 20(1) [acesso em 04 fev 2013]. Disponível: http:// www.scielo.br/pdf/tce/v20n1/06.pdf

14. Santos RL, Sousa MFB, Brasil D, Dourado M. Intervenções de grupo para sobrecarga de cuidadores de pacientes com demência: uma revisão sistemática. Rev. psiquiatr. clín. [Internet] 2011;38(4) [acesso em 04 fev 2013]. Disponível: http://www.hcnet.usp.br/ipq/ revista/vol38/n4/PDF/161.pdf

15. Moll MF, Santos TAPP, Ventura CAA. Sentimentos e percepções de familiares e de pessoas com transtorno bipolar acompanhadas em um centro de atenção psicossocial. Cienc. cuid. saude. [Internet] 2009; 
8(3) [acesso em 04 fev 2013]. Disponível: http:// periodicos.uem.br/ojs/index.php/CiencCuidSaude/ article/view/9049

16. Bosi MLM, Carvalho LB, Ximenes VM, Melo AKS, Godoy MGC. Inovação em saúde mental sob a ótica de usuários de um movimento comunitário no nordeste do Brasil. Ciênc. saúde colet. [Internet] 2012;17(3) [acesso em 04 fev 2013]. Disponível: http://www.scielosp.org/ pdf/csc/v17n3/v17n3a10.pdf

17. Borba LO, Schwartz E, Kantorski LP. A sobrecarga da família que convive com a realidade do transtorno mental. Acta paul. enferm. [Internet] 2008;21(4) [acesso em 04 fev 2013]. Disponível: http://www.scielo.br/pdf/ ape/v21n4/a09v21n4.pdf 